\title{
Dioxygen: What Makes This Triplet Diradical Kinetically Persistent?
}

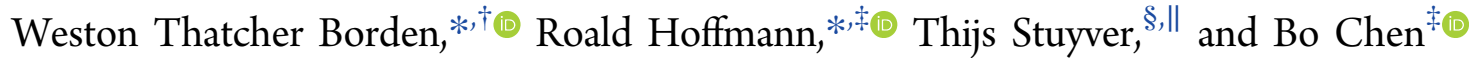 \\ ${ }^{\dagger}$ Department of Chemistry and the Center for Advanced Scientific Computing and Modeling, University of North Texas, 1155 Union \\ Circle, \#305070, Denton, Texas 76203-5017, United States \\ ${ }^{\ddagger}$ Department of Chemistry and Chemical Biology, Cornell University, Baker Laboratory, Ithaca, New York 14853-1301, United States \\ ${ }^{\S}$ Algemene Chemie, Vrije Universiteit Brussel, Pleinlaan 2, 1050 Brussels, Belgium \\ ${ }^{\|}$Research Foundation-Flanders (FWO-Vlaanderen), Egmontstraat 5, 1000 Brussels, Belgium
}

Supporting Information

ABSTRACT: Experimental heats of formation and enthalpies obtained from G4 calculations both find that the resonance stabilization of the two unpaired electrons in triplet $\mathrm{O}_{2}$, relative to the unpaired electrons in two hydroxyl radicals, amounts to $100 \mathrm{kcal} / \mathrm{mol}$. The origin of this huge stabilization energy is described within the contexts of both molecular orbital (MO) and valence-bond (VB) theory. Although $\mathrm{O}_{2}$ is a triplet diradical, the thermodynamic unfavorability of both its hydrogen atom abstraction and oligomerization reactions can be attributed to its very large resonance stabilization energy. The unreactivity of $\mathrm{O}_{2}$ toward both these modes of self-destruction maintains its abundance in the ecosphere and thus its availability to support aerobic life. However, despite the resonance stabilization of the $\pi$ system of triplet $\mathrm{O}_{2}$, the weakness of the $\mathrm{O}-\mathrm{O} \sigma$ bond makes reactions of $\mathrm{O}_{2}$, which eventually lead to cleavage of this bond, very favorable thermodynamically.

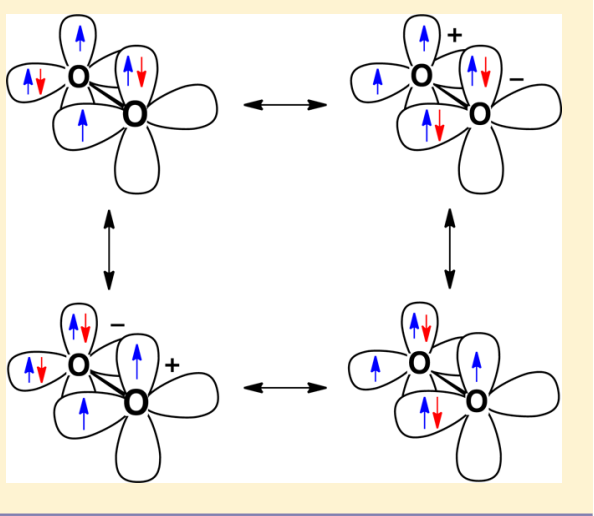

\section{INTRODUCTION}

Dioxygen, $\mathrm{O}_{2}$, is the only molecule in abundance in our environment that is paramagnetic, with a triplet ground state. That does make one sit up. Certainly, we have in the laboratory (or in our infatuation with the internal combustion engine) made other paramagnetic molecules-doublets and triplets most prominently. But, for good reasons, they are not around us in great concentrations. Their unpaired electrons encourage these radicals and diradicals to stabilize themselves by forming bonds to each other.

However, oxygen (throughout this paper we will use the word oxygen for the $\mathrm{O}_{2}$ molecule, which is properly called dioxygen) is abundant. In fact, this triplet diradical constitutes $20.94 \%$ of the earth's atmosphere. ${ }^{1}$ Although chemists have learned to kinetically stabilize other radicals and diradicals by encumbering them with sterically demanding substituents, ${ }^{2}$ oxygen is naked. What causes this triplet diradical to persist?

Oh, yes, oxygen is absolutely essential for many forms of life on our planet. And yet, and yet, when oxygen first came in large amounts into the earth's atmosphere, ${ }^{3}$ presumably produced by photosynthetic bacteria, around 2.3 billion years ago, it occasioned a major killing off of the life forms that had evolved prior to that date. ${ }^{4}$ The life forms that evolved subsequently must have evolved the way they did, in order to cope with, and utilize, molecular oxygen.

Is oxygen "stable"? Is oxygen reactive? Chemists know that there is a distinction between thermodynamics and kinetics. However, the Bell-Evans-Polanyi principle connects the two and indicates that, in general, the relative rates of two reactions are related to which of the two is thermodynamically more favorable. ${ }^{5}$ Therefore, in this paper we will focus on the enthalpies of the reactions of oxygen and of the molecules that are related to it. We will use enthalpic terms-exothermic, endothermic-when we write about thermodynamic stability. We will use the more qualitative terms, persistent and reactive, to describe kinetic proclivities.

Is oxygen stable thermodynamically? By itself, apparently it is, but why this triplet diradical does not react with itself to form oligomers is one of the questions that are addressed in this manuscript.

Is oxygen stable in the presence of other elements? The answer is clearly overall negative. With the exception of gold, absolutely every element reacts exothermically with oxygen. 6,7 In that sense, oxygen is energy-rich; ${ }^{8}$ and not for nothing is it a choice liquid propellant for rockets. ${ }^{9}$ Almost every compound in our bodies, in all living things, with the exception of some inorganic ions such as phosphate and carbonate, is subject to combustion with oxygen. We can burn, and not just with passion.

But, of course, we do not burn. That hydrogen balloon we explode in a general chemistry class does not go off until a flame or spark enters the scene, to allow the reaction to proceed to its thermodynamic nirvana, water. Paper, the making of our civilization (well, at least until now), will not enflame until Fahrenheit $451 .^{10}$ Clearly, oxygen, that molecule which reacts exothermically with almost anything, also has a reasonably high activation barrier to reaction with the same anything.

Received: April 26, 2017

Published: June 14, 2017 
In fact, the barrier to the reaction of oxygen with the $\mathrm{C}-\mathrm{H}$ bonds in any organic molecule is astoundingly high. ${ }^{11}$ But why? $\mathrm{O}_{2}$ in its triplet ground state is a diradical! Think of what you know of how easily a chlorine atom or a hydroxyl radical abstracts hydrogen atoms from alkanes. ${ }^{12}$ Like monoradicals, most diradicals are generally extremely reactive. ${ }^{13}$

Let us put the startling exceptionalism of oxygen another way: How can a molecule constitute one-fifth of the earth's atmosphere, when it is in continual intimate contact with hundreds of thousands of molecules with which its reaction would be downhill in enthalpy? Phenomenologically, the answer to that question is obviously that $\mathrm{O}_{2}$ must have high barriers to reactions with most molecules. Why that is so, and in particular why oxygen has a high barrier to reactions involving the abstraction of hydrogen atoms, is one of the questions that this paper will consider.

An example of the unreactivity of ${ }^{\bullet} \mathrm{OO}^{\bullet}\left({ }^{\bullet} \mathrm{OO}^{\bullet}\right.$ is the notation that we will use throughout this manuscript, in order to emphasize that $\mathrm{O}_{2}$ is a triplet diradical) toward hydrogen atom abstraction is provided by one of the first steps in common autoxidation reactions. Of course, combustion and oxidation mechanisms are unfailingly complex, with a multitude of possible steps following initiation, which typically occurs by formation or introduction of a radical. ${ }^{14-17}$ Chain propagation steps follow, and many different types of radicals can play a role.

However, we focus here on the hydrogen abstraction step in autoxidation reactions (eq 1). This step involves peroxyl radicals, $\mathrm{ROO}^{\bullet}$, not the much more plentiful ${ }^{\bullet} \mathrm{OO}^{\bullet}$ diradicals, which only participate in radical coupling in the second chainpropagating step (eq 2). ${ }^{18}$

$$
\begin{aligned}
& \mathrm{ROO}^{\bullet}+\mathrm{RH} \rightarrow \mathrm{ROOH}+\mathrm{R}^{\bullet} \\
& \mathrm{R}^{\bullet}+{ }^{\bullet} \mathrm{OO}^{\bullet} \rightarrow \mathrm{ROO}^{\bullet}
\end{aligned}
$$

Radical coupling, of which eq 2 is an example, is a common, usually almost barrierless reaction of two radicals, when the radicals are not sterically protected. But ${ }^{\bullet} \mathrm{OO}^{\bullet}$ diradicals do not bond strongly with each other, to form dimers, trimers, or higher oligomers. ${ }^{19}$ There have been numerous studies, both experimental and theoretical, of dimers, trimers, tetramers, and higher aggregates of $\mathrm{O}_{2}$. The consensus that has emerged is that these are weakly bound (yet quite detectable and capable of being studied spectroscopically) by predominantly dispersion forces. $^{20,21}$ Thus, ${ }^{\bullet} \mathrm{OO}^{\bullet}$ remains a diatomic gas under ambient earth conditions, rather than being sequestered in oligomers. In this regard oxygen is quite different from sulfur, for which the most stable form is not triplet $S_{2}\left({ }^{\bullet} S S^{\bullet}\right)$, but the tetramer, $S_{8}$.

In this paper, we use a combination of thermodynamic data, where available, and high level calculations to investigate the reason for the unreactivity of triplet ${ }^{\bullet} \mathrm{OO}^{\bullet}$ toward (a) hydrogen abstraction and (b) oligomerization. Triplet ${ }^{\bullet} \mathrm{SS} \boldsymbol{\bullet}^{\bullet}$ provides a suitable comparison with triplet ${ }^{\circ} \mathrm{OO}^{\circ}$ in both types of reactions. We also investigate the origin of the large enthalpy release that is associated with reactions that result in the eventual cleavage of the $\mathrm{O}-\mathrm{O} \sigma$ bond in $\mathrm{O}_{2}$.

\section{METHODOLOGY}

Where available, heats of formation of reactants and products in several reactions of ${ }^{\bullet} \mathrm{OO}{ }^{\bullet}$ were obtained from Argonne National Laboratory's Active Thermochemical Tables (ATcT). ${ }^{22}$ From these values of $\Delta_{\mathrm{f}} H^{\circ}(298.15 \mathrm{~K})$, the enthalpies of reaction, $\Delta H(298.15 \mathrm{~K})$, were calculated.
Fortunately, the relevant heats of formation are reasonably abundant for the $\mathrm{O} / \mathrm{H}$ molecules discussed in this manuscript, due to their importance in combustion and atmospheric chemistry. The Active Thermochemical Tables represent a systematic approach to thermochemistry, combining experiment and theory. Previous experience has shown that the enthalpies of reactions, computed with ATcT heats of formation, are in excellent agreement with the values obtained from high level calculations. ${ }^{23}$

Enthalpies of reactants and products were also computed at the G4 level of theory, ${ }^{24}$ and these enthalpies were used to obtain G4 values of $\Delta H(298.15 \mathrm{~K})$ for all of the reactions in this paper. Where comparisons of the calculated $\mathrm{G} 4$ values with the largely experimental ATcT values of $\Delta H(298.15 \mathrm{~K})$ are possible (e.g., in the first four reactions in Table 1), the

Table 1. Enthalpies of Reaction, $\Delta H(298.15 \mathrm{~K})$ in $\mathrm{kcal} / \mathrm{mol}$, Obtained from Experimental Heats of Formation,

\begin{tabular}{|c|c|c|c|}
\hline \multirow[b]{2}{*}{$\begin{array}{l}\text { reaction } \\
\text { label }\end{array}$} & \multirow[b]{2}{*}{ reaction } & \multicolumn{2}{|c|}{$\Delta H(298.15 \mathrm{~K})$} \\
\hline & & G4 value & $\begin{array}{l}\text { ATcT } \\
\text { value }\end{array}$ \\
\hline A & $\bullet \mathrm{OH}+\mathrm{H}_{2} \mathrm{O}_{2} \rightarrow \mathrm{H}_{2} \mathrm{O}+{ }^{\bullet} \mathrm{OOH}$ & -31.6 & -31.0 \\
\hline B & $\bullet \mathrm{OH}+\bullet^{\bullet} \mathrm{OOH} \rightarrow \mathrm{H}_{2} \mathrm{O}+\bullet^{\bullet} \mathrm{OO}$ & -69.0 & -69.2 \\
\hline $\mathrm{C}$ & $2^{\bullet} \mathrm{OOH} \rightarrow \mathrm{HOOH}+\bullet^{\bullet} \mathrm{OO}^{\bullet}$ & -37.4 & -38.2 \\
\hline $\mathrm{D}$ & $2^{\bullet} \mathrm{OH}+\mathrm{HOOH} \rightarrow 2 \mathrm{H}_{2} \mathrm{O}+{ }^{\bullet} \mathrm{OO}{ }^{\bullet}$ & -100.6 & -100.2 \\
\hline $\mathrm{E}$ & $3^{\bullet} \mathrm{OO}^{\bullet} \rightarrow \mathrm{O}_{6}($ cyclic $)$ & +79.4 & \\
\hline $\mathrm{F}$ & $4^{\bullet} \mathrm{OO}^{\bullet} \rightarrow \mathrm{O}_{8}($ cyclic $)$ & +94.6 & \\
\hline G & $2 \cdot \mathrm{OOH} \rightarrow \mathrm{HOOOOH}$ & -15.4 & \\
\hline $\mathrm{H}$ & $\cdot \mathrm{SH}+\mathrm{H}_{2} \mathrm{~S}_{2} \rightarrow \mathrm{H}_{2} \mathrm{~S}+\bullet \cdot \mathrm{SSH}$ & -17.5 & \\
\hline I & $\bullet^{\circ} \mathrm{SH}+\bullet^{\bullet} \mathrm{SSH} \rightarrow \mathrm{H}_{2} \mathrm{~S}+{ }^{\bullet} \mathrm{SS}^{\bullet}$ & -33.4 & \\
\hline $\mathrm{J}$ & $2^{\bullet} \mathrm{SSH} \rightarrow \mathrm{HSSH}+\bullet^{\bullet} \mathrm{SS}^{\bullet}$ & -15.9 & \\
\hline $\mathrm{K}$ & $2 \cdot{ }^{\bullet} \mathrm{SH}+\mathrm{HSSH} \rightarrow 2 \mathrm{H}_{2} \mathrm{~S}+\bullet^{\bullet} \mathrm{SS}^{\bullet}$ & -50.9 & \\
\hline $\mathrm{L}$ & $3^{\bullet} \mathrm{SS}^{\bullet} \rightarrow \mathrm{S}_{6}($ cyclic $)$ & -70.8 & \\
\hline M & $4^{\bullet} \mathrm{SS}^{\bullet} \rightarrow \mathrm{S}_{8}($ cyclic $)$ & -103.0 & \\
\hline $\mathrm{N}$ & $2^{\bullet} \mathrm{SSH} \rightarrow \mathrm{HSSSSH}$ & -41.2 & \\
\hline
\end{tabular}
$\Delta_{\mathrm{f}} H^{\circ}(298.15 \mathrm{~K})$, and from G4 Calculations

agreement between the two types of values is within $\pm 1.0 \mathrm{kcal} /$ mol. Therefore, it seems reasonable to suppose that the G4 values of $\Delta H(298.15 \mathrm{~K})$ for all of the reactions in this paper are probably quite accurate.

\section{RESULTS AND DISCUSSION}

The experimental and G4 values of $\Delta H(298.15 \mathrm{~K})$ for the reactions discussed in this manuscript are assembled in Table 1. The experimental values of $\Delta_{\mathrm{f}} H^{\circ}(298.15 \mathrm{~K})$ and the G4 enthalpies of the reactants and products, from which the G4 $\Delta H(298.15 \mathrm{~K})$ values in Table 1 were derived, are given in Table S1.

Hydroperoxyl Radical ('OOH). The three-electron, twocenter $\pi$ bonds in the $\mathrm{O}_{2}$ molecule (about which we will have much more to say) are like those in the hydroperoxyl radical $\left({ }^{\bullet} \mathrm{OOH}\right)$. Actually, it is useful to travel to ${ }^{\bullet} \mathrm{OO}^{\bullet}$ via ${ }^{\bullet} \mathrm{OOH}$, so we begin by computing the resonance stabilization of the - $\mathrm{OOH}$ radical. This important species has a ${ }^{2} \mathrm{~A}^{\prime \prime}$ ground state. It is a $\pi$ radical, with $\mathrm{O}-\mathrm{O} 1.33 \AA$, O-H $0.97 \AA$, and an $\mathrm{OOH}$ angle of $104.3^{\circ} .^{25}$ The stabilization energy of ${ }^{\circ} \mathrm{OOH}$ can be defined by the enthalpy of the reaction

$$
\bullet{ }^{\bullet} \mathrm{OH}+\mathrm{H}_{2} \mathrm{O}_{2} \rightarrow \mathrm{H}_{2} \mathrm{O}+{ }^{\bullet} \mathrm{OOH}
$$

in which the localized hydroxyl radical is converted to the delocalized peroxyl radical. Equation 3 in the text is equation $\mathrm{A}$ 
in Table 1. (We will consistently use letters to label chemical equations in Table 1, and numbers for those that appear in the text.) Entry A in Table 1 shows that an $\mathrm{O}-\mathrm{H}$ bond in $\mathrm{H}_{2} \mathrm{O}_{2}$ is ca. $31-32 \mathrm{kcal} / \mathrm{mol}$ weaker than an $\mathrm{O}-\mathrm{H}$ bond in $\mathrm{H}_{2} \mathrm{O}$, presumably due to the resonance stabilization of ${ }^{\bullet} \mathrm{OOH}$, relative to ${ }^{\circ} \mathrm{OH}$.

The qualifier "presumably" is used for good reasons. As usual in thermodynamic considerations of stability, reasonable men and women can, and often do, turn the horse around. ${ }^{26}$ For example, some of the exothermicity of the reaction A could also be attributed to some destabilizing feature of one of the reactants, hydrogen peroxide. Lone pair repulsion might serve admirably, but the gauche conformation of $\mathrm{H}_{2} \mathrm{O}_{2}$ minimizes the destabilizing overlap between the pairs of electrons on the two oxygens and replaces it with the more stabilizing hyperconjugative interactions between the lone pairs and the $\mathrm{O}-\mathrm{H}$ $\sigma^{*}$ orbitals. $^{27}$ Therefore, we attribute most, if not all, of the exothermicity of reaction $\mathrm{A}$ in Table 1 to the resonance stabilization of ${ }^{\bullet} \mathrm{OOH}$.

The resonance stabilization of ${ }^{\bullet} \mathrm{OOH}$ is due to the presence of a three-electron, two-center $\pi$ bond between the oxygens. ${ }^{28}$ In such a bond two oxygen electrons occupy a $\pi$ MO that is $\mathrm{O}-\mathrm{O}$ bonding, and the unpaired electron occupies a $\pi^{*} \mathrm{MO}$ that is $\mathrm{O}-\mathrm{O}$ antibonding. Consequently, there is, on net, one bonding electron in the three-electron, two-atom $\pi$ bond in ${ }^{\bullet} \mathrm{OOH}$; and this $\pi$ bonding electron serves to stabilize ${ }^{\bullet} \mathrm{OOH}$, relative to ${ }^{\circ} \mathrm{OH}$.

In valence bond (VB) theory, the resonance stabilization in a three-electron, two-center $\pi$ bond is attributed to a contribution from the second resonance structure in Figure 1. In this type of

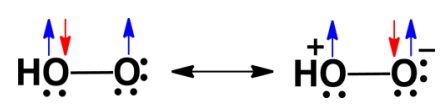

Figure 1. Resonance stabilization of the hydroperoxyl radical by threeelectron, two-center bonding. For the sake of visual clarity, we have colored the $\alpha$-spin electrons blue and $\beta$-spin electrons red in this and in subsequent figures.

resonance stabilization, one nonbonding $\pi$ electron on the oxygen that has an octet of electrons in the first structure in Figure 1 is delocalized in the second structure into the singly occupied $2 \mathrm{p}-\pi \mathrm{AO}$ on the other oxygen. If the unpaired electron is assumed to have $\alpha$-spin, the electron that is delocalized into the $\mathrm{AO}$ occupied by this electron must, of course, have $\beta$-spin.

We will subsequently return to a detailed discussion of the $\mathrm{MO}$ and VB descriptions of the three-electron, two-center, $\pi$ bonding in ${ }^{\circ} \mathrm{OO}^{\circ}$.

The Dioxygen Triplet Diradical ( $\left.{ }^{\bullet} \mathrm{OO}{ }^{\bullet}\right)$. The ${ }^{\bullet} \mathrm{OO}{ }^{\bullet}$ triplet diradical has two orthogonal sets of $\pi$ MOs. Therefore, on breaking the $\mathrm{O}-\mathrm{H}$ bond in $\mathrm{HOO}^{\bullet}$ to form ${ }^{\bullet} \mathrm{OO}^{\bullet}$, one might have expected that the reaction

$$
{ }^{\bullet} \mathrm{OH}+{ }^{\bullet} \mathrm{OOH} \rightarrow \mathrm{H}_{2} \mathrm{O}+{ }^{\bullet} \mathrm{OO}^{\bullet}
$$

like the reaction in eq 3 , would be exothermic by $31-32 \mathrm{kcal} /$ mol, because in the reaction in eq 4 a second three-electron, two-center $\pi$ bond can be formed between the oxygens.

However, the reaction in eq 4 , which is reaction B in Table 1 , is both calculated and found experimentally to be exothermic by $69 \mathrm{kcal} / \mathrm{mol}$. Indeed, reaction $\mathrm{C}$ in Table 1 , which is the difference between reactions $\mathrm{B}$ and $\mathrm{A}$, shows that breaking the $\mathrm{O}-\mathrm{H}$ bond in ${ }^{\bullet} \mathrm{OOH}$, to form ${ }^{\bullet} \mathrm{OO}^{\bullet}$, actually requires $37-38$ $\mathrm{kcal} / \mathrm{mol}$ less enthalpy than breaking an $\mathrm{O}-\mathrm{H}$ bond in $\mathrm{HOOH}$, to form $\bullet \mathrm{OOH}$.

Looked at in reverse, this result means that hydrogen atom abstraction by ${ }^{\bullet} \mathrm{OO}^{\bullet}$ is $37-38 \mathrm{kcal} / \mathrm{mol}$ less favorable enthalpically than hydrogen atom abstraction by ${ }^{\circ} \mathrm{OOH}$. Therefore, applying the Bell-Evans-Polanyi principle, ${ }^{5}$ it is certainly understandable that $\mathrm{ROO}^{\circ}$ can abstract a hydrogen from $\mathrm{R}-\mathrm{H}$ in the first chain propagating reaction of an autoxidation reaction (eq 1 ), but ${ }^{\bullet} \mathrm{OO}^{\bullet}$ apparently does not abstract a hydrogen from $\mathrm{R}-\mathrm{H}$, even when ${ }^{\circ} \mathrm{OO}^{\bullet}$ is present in very large excess.

In this connection we wish to mention a detailed study of the $2 \mathrm{H}_{2}+\mathrm{O}_{2} \rightarrow 2 \mathrm{H}_{2} \mathrm{O}$ reaction by Filatov, Reckien, Peyerimhoff, and Shaik. ${ }^{29}$ Their paper was informed by oxidation modes in metal-oxene and mono-oxygenase enzymes that the Shaik group had studied. Both the triplet and singlet surfaces for the abstraction of a hydrogen atom from $\mathrm{H}_{2}$ by $\mathrm{O}_{2}$ were calculated, and it was found that this reaction encounters very large barriers of 60.7 and $66.4 \mathrm{kcal} / \mathrm{mol}$, respectively, for the triplet and the singlet states of $\mathrm{O}_{2}$.

How much of the $60.7 \mathrm{kcal} / \mathrm{mol}$ calculated barrier height to abstraction of a hydrogen atom from $\mathrm{H}_{2}$ by triplet ${ }^{\bullet} \mathrm{OO}^{\bullet}$ is simply due to thermochemistry? Filatov et al. calculate that this reaction is energetically unfavorable by $58.0 \mathrm{kcal} / \mathrm{mol}^{29}$ Therefore, more than $95 \%$ of the calculated barrier height is due to the unfavorable energetics of this hydrogen abstraction reaction. It is clear that the kinetics of this reaction are dominated by its thermochemistry.

Returning to reaction $\mathrm{C}$ in Table 1, it can also be interpreted as indicating that the electron delocalization in ${ }^{\circ} \mathrm{OO}^{\bullet}$ is $37-38$ $\mathrm{kcal} / \mathrm{mol}$ more stabilizing than the electron delocalization in two molecules of ${ }^{\bullet} \mathrm{OOH}$. Either MO or VB theory can be used to explain the reason for the extra stability of $\mathrm{O}_{2}$; and, as discussed in the following sections, the two explanations turn out to be similar.

However, it should first be noted that it is to Linus Pauling that we owe the recognition of the special thermodynamic stability of the two, three-electron, $\pi$ bonds in $\mathrm{O}_{2}$, relative to the strength of the $\mathrm{O}-\mathrm{O} \sigma$ bond. $^{30,31}$ In section 2 of the Supporting Information for this manuscript we describe how Pauling viewed $\mathrm{O}_{2}$.

Resonance Structures for the ${ }^{\circ} \mathrm{OO}^{\bullet}$ Diradical. Shown in Figure 2 are the four resonance structures that arise from assigning six electrons-four of $\alpha$-spin and two of $\beta$-spin-to the four $2 \mathrm{p}_{x}$ and $2 \mathrm{p}_{y} \pi$ AOs in the triplet ground state of the oxygen molecule. As shown in Figure 2, one $\alpha$-spin electron occupies each $2 \mathrm{p}-\pi \mathrm{AO}$. The $\beta$-spin electron in each of the two

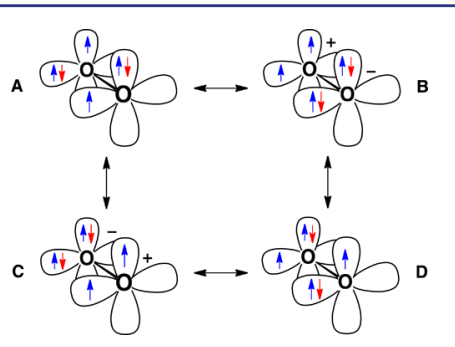

Figure 2. Possible distributions, $\mathbf{A}-\mathbf{D}$ of the two $\beta$-spin electrons in the two orthogonal $\pi$ systems of triplet ${ }^{\circ} \mathrm{OO}^{\bullet}$. The four $\alpha$-spin electrons each occupy one of the four $2 \mathrm{p}-\pi$ AOs; so, as shown in resonance structures $\mathbf{A}-\mathbf{D}$, it is only the $\beta$-spin electrons that are delocalized. 
orthogonal $\pi$ systems is delocalized over the $2 \mathrm{p}-\pi$ AOs of both oxygen atoms. $^{32}$

The two zwitterionic structures, $\mathbf{B}$ and $\mathbf{C}$, represent delocalization of the $\beta$-spin electrons in the two orthogonal $\pi$ systems in a fashion similar to that shown in the second resonance structure for peroxyl radical in Figure 1. Thus, if resonance structures $\mathbf{A}, \mathbf{B}$, and $\mathbf{C}$ represented accurately the ${ }^{\circ} \mathrm{OO}^{\bullet}$ wave function, one would expect that the stabilization provided by electron delocalization in ${ }^{\bullet} \mathrm{OO}^{\bullet}$ would be about the same as that in two peroxyl radicals. Therefore, the enthalpy of reaction $\mathrm{C}$ in Table 1 would be close to zero, instead of having its actual value of $37-38 \mathrm{kcal} / \mathrm{mol}$.

It is the contribution from resonance structure $\mathbf{D}$ in Figure 1 that makes the delocalization energy of ${ }^{\bullet} \mathrm{OO}^{\bullet} 37-38 \mathrm{kcal} / \mathrm{mol}$ larger than that that of two molecules of ${ }^{\bullet} \mathrm{OOH}$. In structure $\mathbf{D}$, as in structure $\mathbf{A}$, there is no charge separation, as there is in resonance structures $\mathbf{B}$ and $\mathbf{C}$. Therefore, resonance structures $\mathbf{A}$ and $\mathbf{D}$ in Figure 2 are expected to dominate the wave function for the electrons in the two orthogonal $\pi$ systems.

The picture in Figure 2 of the bonding in $\mathrm{O}_{2}$ is patently a VB description; and it seems, at first, to have no relation to the MO representation of the triplet state of the $\mathrm{O}_{2}$ molecule. The correspondence between the $\mathrm{VB}$ and $\mathrm{MO}$ pictures is delineated in the next section.

The MO Wave Function for Triplet ${ }^{\circ} \mathrm{OO}{ }^{\bullet}$ and the Importance of Including Electron Correlation in this Wave Function. The MO description of triplet $\mathrm{O}_{2}$ begins with two, orthogonal, bonding $\pi$ MOs, ${ }^{33}$

$$
\begin{aligned}
& \pi_{x}=\frac{1}{\sqrt{2}}\left(\phi_{1 x}+\phi_{2 x}\right) \\
& \pi_{y}=\frac{1}{\sqrt{2}}\left(\phi_{1 y}+\phi_{2 y}\right)
\end{aligned}
$$

and their antibonding $\pi^{*}$ partners, ${ }^{34}$

$$
\begin{aligned}
& \pi_{x}^{*}=\frac{1}{\sqrt{2}}\left(\phi_{1 x}-\phi_{2 x}\right) \\
& \pi_{y}^{*}=\frac{1}{\sqrt{2}}\left(\phi_{1 y}-\phi_{2 y}\right)
\end{aligned}
$$

An $\alpha$ - and a $\beta$-spin electron are assigned to each of the bonding $\pi$ MOs, and an $\alpha$-spin electron is assigned to each of the antibonding $\pi^{*}$ MOs. Thus, the restricted, open-shell, Hartree-Fock (ROHF) wave function for triplet $\mathrm{O}_{2}$ can be written

$$
\Psi(\mathrm{ROHF})=\left|. . . \pi_{x}^{\alpha} \pi_{x}^{\beta} \pi_{y}^{\alpha} \pi_{y}^{\beta} \pi_{x}^{* \alpha} \pi_{y}^{* \alpha}\right\rangle
$$

Since the MOs for two electrons of the same spin can be added or subtracted, without changing a many-electron wave function, the pair of $\alpha$-spin electrons in the $\pi$ and $\pi^{*}$ MOs in each of the two orthogonal $\pi$ systems of triplet ${ }^{\bullet} \mathrm{OO}^{\bullet}$ can be taken to be localized, one in each $\mathrm{AO}$, as shown in each of the four resonance structures in Figure 2. Since only the $\beta$-spin electrons are delocalized, the ROHF wave function in eq 7 can be abbreviated as

$$
\Psi(\mathrm{ROHF})=\left|. . \pi_{x}^{\beta} \pi_{y}^{\beta}\right\rangle
$$

eq 8 shows that in $\Psi(\mathrm{ROHF})$ the two $\beta$-spin electrons, one in $\pi_{x}$ and one in $\pi_{y}$, move independently of each other. Therefore, all four of the structures in Figure 2 have equal weights in the $\mathrm{ROHF}$ wave function for the triplet ${ }^{\bullet} \mathrm{OO}{ }^{\bullet}$ diradical.
Although the ROHF wave function for ${ }^{\bullet} \mathrm{OO}^{\bullet}$ fails to weight structures $\mathbf{A}$ and $\mathbf{D}$ more heavily than structures $\mathbf{B}$ and $\mathbf{C}$, the ROHF wave function does make the delocalization energy, calculated for ${ }^{\bullet} \mathrm{OO}^{\bullet}$, larger than that for two molecules of - $\mathrm{OOH}$. When the energy of reaction $\mathrm{C}$ in Table 1 ,

$$
2 \mathrm{HOO}^{\bullet} \rightarrow \mathrm{HOOH}+{ }^{\circ} \mathrm{OO}^{\bullet}
$$

is computed at the ROHF/aug-cc-pVTZ level of theory, the reaction is determined to be energetically favorable by 22.5 $\mathrm{kcal} / \mathrm{mol}$. However, this ROHF energetic favorability is about $15 \mathrm{kcal} / \mathrm{mol}$ less than both the experimental and the G4 exothermicities of reaction $\mathrm{C}$ in Table 1.

In order to weight more heavily the contribution of the nonzwitterionic structures, $\mathbf{A}$ and $\mathbf{D}$, in the wave function for triplet ${ }^{\circ} \mathrm{OO}^{\bullet}$, correlation between the motions of the $\beta$-spin electrons can be introduced by adding a second configuration to the ROHF wave function. The configuration that needs to be added can be abbreviated as $\left|. . . \pi_{x}^{* \beta} \pi_{y}^{* \beta}\right\rangle$, in which each $\beta$-spin electron is assigned to the antibonding $\pi^{*} \mathrm{MO}$ of one of the two orthogonal $\pi$ systems (eq 6). The resulting twoconfiguration (TC)SCF wave function for the $\beta$-spin electrons in triplet ${ }^{\bullet} \mathrm{OO}^{\bullet}$ is then

$$
\Psi(\mathrm{TCSCF})=\left|. . . \pi_{x}^{\beta} \pi_{y}^{\beta}\right\rangle-\lambda^{2}\left|\ldots \pi_{x}^{* \beta} \pi_{y}^{* \beta}\right\rangle
$$

where the mixing coefficient, $\lambda^{2}$, must be optimized variationally.

In eq 10 , two electrons are excited from bonding $\pi$ MOs in the first configuration to antibonding $\pi^{*}$ MOs in the second configuration. Therefore, the energy of the second configuration is considerably higher than that of the first. Consequently, the mixing coefficient, $\lambda^{2}$, in eq 10 is certainly much less than 1 .

The spatial part of the TCSCF wave function in eq 10 can be factored; and an unnormalized version of the spatial part of the TCSCF wave function in eq 10 can be rewritten as

$$
\Psi(\mathrm{TCSCF})=\left|\ldots\left(\pi_{x}+\lambda \pi_{x}^{*}\right)\left(\pi_{y}-\lambda \pi_{y}^{*}\right)\right\rangle+\left|\ldots\left(\pi_{x}-\lambda \pi_{x}^{*}\right)\left(\pi_{y}+\lambda \pi_{y}^{*}\right)\right\rangle
$$

Substituting for $\pi$ from eq 5 and for $\pi^{*}$ from eq 6 , eq 11 becomes

$$
\begin{aligned}
& \Psi(\mathrm{TCSCF})=\left|\ldots\left[(1+\lambda) \phi_{1 x}+(1-\lambda) \phi_{2 x}\right]\left[(1-\lambda) \phi_{1 y}+(1+\lambda) \phi_{2 y}\right]\right\rangle \\
& \quad+\left|\ldots\left[(1-\lambda) \phi_{1 x}+(1+\lambda) \phi_{2 x}\right]\left[(1+\lambda) \phi_{1 y}+(1-\lambda) \phi_{2 y}\right]\right\rangle
\end{aligned}
$$

It can easily be seen that the TCSCF wave function in eq 12 correlates the motions of the $\beta$-spin electrons in the two orthogonal $\pi$ systems of ${ }^{\bullet} \mathrm{OO}^{\bullet}$, because in the limit where $\lambda=$ 1 , eq 12 becomes

$$
\left.\Psi(\mathrm{TCSCF})=\mathrm{I}_{. .} \phi_{1 x} \phi_{2 y}\right\rangle+\left|. . . \phi_{2 x} \phi_{1 y}\right\rangle
$$

The TCSCF wave function in eq 13 correlates the $\beta$-spin electrons in the two different $\pi$ systems of $\mathrm{O}_{2}$ perfectly, by always keeping these electrons on different oxygen atoms, one electron on oxygen 1 and the other on oxygen 2 , thus minimizing the Coulombic repulsion between them. Therefore, if $\lambda=1$, only the two non-zwitterionic electron distributions, $\mathbf{A}$ and $\mathbf{D}$, in Figure 1 would be present in ${ }^{\bullet} \mathrm{OO}^{\bullet} .^{35}$

However, $\lambda=1$ means that the $\pi$ and $\pi^{*}$ MOs of ${ }^{\bullet} \mathrm{OO}^{\bullet}$ would be equally occupied. Then there would be no $\pi$ bonding in either of the two orthogonal $\pi$ systems of ${ }^{\bullet} \mathrm{OO}^{\bullet}$. Clearly, $\lambda=$ 1 is a limit that will not be reached in the TCSCF wave function for $\mathrm{O}_{2}$. 
In an actual TCSCF calculation on triplet ${ }^{\circ} \mathrm{OO}^{\bullet}, \lambda$ is variationally optimized, so that the energy of the TCSCF wave function is minimized by finding the best compromise between maximizing bonding in the two orthogonal $\pi$ systems and minimizing the Coulombic repulsion between the $\beta$-spin electrons in them. Going from an ROHF calculation on ${ }^{\circ} \mathrm{OO}^{\bullet}$ to a TCSCF calculation lowers the calculated energy of triplet ${ }^{\circ} \mathrm{OO}^{\bullet}$ by $20.7 \mathrm{kcal} / \mathrm{mol}$ and thus almost doubles the energetic favorability of the reaction in eq 9 , from 22.5 to 43.2 $\mathrm{kcal} / \mathrm{mol}$.

Using the TCSCF energy for ${ }^{\bullet} \mathrm{OO}^{\bullet}$ in eq 10 overestimates by $5-6 \mathrm{kcal} / \mathrm{mol}$ the stabilization of ${ }^{\circ} \mathrm{OO}{ }^{\bullet}$ by electron delocalization. Nevertheless the TCSCF value of $43.2 \mathrm{kcal} /$ mol for the energy of the reaction in eq 9 comes much closer to the G4 and experimental values of $37-38 \mathrm{kcal} / \mathrm{mol}$ than does the ROHF value of only $22.5 \mathrm{kcal} / \mathrm{mol}$. As already noted, correlation between the $\beta$-spin electrons in the two $\pi$ systems of ${ }^{\bullet} \mathrm{OO}^{\bullet}$ is totally absent from the ROHF wave function for triplet ${ }^{\circ} \mathrm{OO}^{\bullet}$, and this type of electron correlation plays an important role in the stabilization of triplet ${ }^{\bullet} \mathrm{OO}^{\bullet}$ by the pair of three-electron, two-center $\pi$ bonds that this diradical contains.

VB Description of the Origin of the Thermodynamic Stability of the Triplet ${ }^{\bullet} \mathrm{OO}^{\bullet}$ Diradical. VB theory, like MO theory, does come to the conclusion that $\mathrm{O}_{2}$ is a diradical with a triplet ground state. ${ }^{36-41}$ The malignment of VB theory for its supposed failure of characterizing the ground state of $\mathrm{O}_{2}$ is undeserved. Indeed, advanced $\mathrm{VB}$ calculations on $\mathrm{O}_{2}$ lead to results that are as accurate as advanced wave function methods (vide infra). MO theory and valence bond theory can, in fact, be connected to each other through the so-called Generalized Valence Bond (GVB) theory, pioneered by Goddard and coworkers. ${ }^{42,43}$

How does VB theory account for the $37-38 \mathrm{kcal} / \mathrm{mol}$ greater stabilization by electron delocalization of triplet ${ }^{\circ} \mathrm{OO}^{\bullet}$, relative to two molecules of ${ }^{\bullet} \mathrm{OOH}$ ?

The four structures in Figure 2 represent the most important resonance structures for triplet ${ }^{\circ} \mathrm{OO}{ }^{\bullet}$. $\mathrm{VB}$ calculations by McWeeny ${ }^{44}$ found that the optimal VB wave function is

$$
\Psi(\mathrm{VB})=0.59(\mathbf{A}+\mathbf{D})-0.23(\mathbf{B}+\mathbf{C})
$$

Not surprisingly, the non-zwitterionic structures, $\mathbf{A}$ and $\mathbf{D}$, have a much higher weight than the zwitterionic structures, $\mathbf{B}$ and $\mathbf{C}$, in this wave function.

Why are structures $\mathbf{B}$ and $\mathbf{C}$ present in $\Psi(\mathrm{VB})$ in eq 14 if they are much higher in energy than structures $\mathbf{A}$ and $\mathbf{D}$ ? As pointed out by Harcourt in $1992,{ }^{45}$ structures B and C differ from structures $\mathbf{A}$ and $\mathbf{D}$ by the shift of just one electron; whereas, $\mathbf{A}$ and $\mathbf{D}$ (and $\mathbf{B}$ and $\mathbf{C}$ ) differ from each other by the shift of two electrons. In VB theory, greater stabilization results from one-electron than from two-electron shifts between resonance structures. Therefore, the interaction of structures $\mathbf{A}$ and $\mathbf{D}$ with $\mathbf{B}$ and $\mathbf{C}$ provides more resonance energy than the interaction of structures $\mathbf{A}$ and $\mathbf{D}$ with each other.

Harcourt computed the energy of the VB wave function in which structures A, B, C, and D were constrained to have equal weights. This constrained VB wave function was calculated by Harcourt to be $25.9 \mathrm{kcal} / \mathrm{mol}$ higher in energy than the $\mathrm{VB}$ wave function in eq 14, in which the coefficients of the resonance structures are optimized.

Since the VB wave function in eq 14 should be similar to the TCSCF MO wave function in eq 10, and since the VB wave function with all of the coefficients constrained to be equal should be equivalent to the ROHF wave function in eq 8 , it is not surprising that Harcourt's energy difference of $25.9 \mathrm{kcal} /$ mol between the unconstrained and constrained $\mathrm{VB}$ wave functions is similar in size to the energy difference of $20.7 \mathrm{kcal} /$ mol between the TCSCF and ROHF MO wave functions.

Harcourt also computed the energy of the VB wave function consisting only of structures $\mathbf{A}-\mathbf{C}$ and omitting structure $\mathbf{D}$. This should correspond to an ${ }^{\bullet} \mathrm{OO}^{\bullet}$ molecule in which the stabilization should be approximately the same as that in two molecules of 'OOH. Harcourt's 1992 calculations found the energy difference between this incomplete $\mathrm{VB}$ wave function and the VB wave function in eq 14 to be $25.6 \mathrm{kcal} / \mathrm{mol}$. This energy difference is about $11-12 \mathrm{kcal} / \mathrm{mol}$ smaller than the experimental and G4 enthalpies of reaction $\mathrm{C}$ in Table 1, which find the delocalization energy in triplet ${ }^{\circ} \mathrm{OO}^{\bullet}$ to be $37-38$ $\mathrm{kcal} / \mathrm{mol}$ larger than that in two molecules of ${ }^{\bullet} \mathrm{OOH}$.

Harcourt also compared the energy of the VB wave function in eq 14 with the energy calculated for just structure A, which has no resonance stabilization. He found that delocalization stabilizes the VB wave function in eq 14 by $77.2 \mathrm{kcal} / \mathrm{mol}$, relative to structure $\mathbf{A}$. Using a much better basis set, $\mathrm{Su}$ et al. calculated that a VB wave function consisting of structures A$\mathbf{D}$ is $102.6 \mathrm{kcal} / \mathrm{mol}$ lower than structure $\mathbf{A}$ alone. ${ }^{40}$ As discussed in the next section, both G4 calculations and experimental heats of formation find that the total resonance energy of triplet ${ }^{\bullet} \mathrm{OO}^{\bullet}$ is very close to the VB value, computed by Su et al.

The Resonance Energy of ${ }^{\circ} \mathrm{OO}^{\bullet}$. Summing reactions A and $\mathrm{B}$ in Table 1 gives

$$
2^{\circ} \mathrm{OH}+\mathrm{HOOH} \rightarrow 2 \mathrm{H}_{2} \mathrm{O}+{ }^{\bullet} \mathrm{OO}^{\bullet}
$$

which is reaction $\mathrm{D}$ in Table 1 . The enthalpy of this reaction is $-100.6 \mathrm{kcal} / \mathrm{mol}$, as computed by G4, and $-100.2 \mathrm{kcal} / \mathrm{mol}$ from experimental heats of formation.

The very high exothermicity of this reaction can be viewed as being due to the difference in energy between having two unpaired electrons localized on two hydroxyl radicals and having them in a pair of two-center, three-electron bonds in an oxygen molecule. Thus, the enthalpy of the reaction in eq 14 (equation $\mathrm{D}$ in Table 1 ) seems to be a reasonable definition of the delocalization or resonance energy of $\mathrm{O}_{2}{ }^{46}$

Of course, resonance energies always depend on the reference state. If one were to use, instead of equation $\mathrm{D}$, equation $\mathrm{C}$ of Table 1 to define the resonance energy of ${ }^{\bullet} \mathrm{OO}{ }^{\bullet}$, one would get $37-38 \mathrm{kcal} / \mathrm{mol}$, with the reference now being two ${ }^{\circ} \mathrm{OOH}$ radicals. As shown in equation $\mathrm{A}$, each ${ }^{\circ} \mathrm{OOH}$ radical is resonance-stabilized by $31-32 \mathrm{kcal} / \mathrm{mol}$. Thus, the $100 \mathrm{kcal} / \mathrm{mol}$ figure for the resonance stabilization of ${ }^{\bullet} \mathrm{OO}^{\bullet}$ contains contributions from the stabilization by each of the two, orthogonal, three-electron bonds in this diradical, plus the additional, synergistic, stabilization that comes from the presence of both three-electron bonds in the same molecule.

Accepting that eq 15 (equation D of Table 1) is a good measure of the resonance stabilization of the oxygen molecule means that the $100 \mathrm{kcal} / \mathrm{mol}$ resonance energy of triplet ${ }^{\circ} \mathrm{OO}^{\bullet}$ is approximately three times the size of Kistiakowski's value of $36.5 \mathrm{kcal} / \mathrm{mol}$ for the resonance energy of benzene, relative to the double bonds in three molecules of cyclohexene. ${ }^{47}$ Who would have guessed that the resonance stabilization of ${ }^{\bullet} \mathrm{OO}^{\bullet}$ is this large?

Why $\mathrm{O}_{6}$ and $\mathrm{O}_{8}$ Are Not the Thermodynamically Most Stable Allotropes of Oxygen. The ca. $100 \mathrm{kcal} / \mathrm{mol}$ resonance energy of triplet ${ }^{\circ} \mathrm{OO}^{\bullet}$ is the reason that G4 calculations predict its trimerization to cyclic $\mathrm{O}_{6}$ in reaction $\mathrm{E}$ 
of Table $1^{48}$ and its tetramerization to cyclic $\mathrm{O}_{8}$ in reaction $\mathrm{F}$ to be endothermic by, respectively, 79.4 and $94.6 \mathrm{kcal} / \mathrm{mol}$. Although both $\mathrm{O}_{6}$ and $\mathrm{O}_{8}$ are local minima, their formation from triplet $\mathrm{O}_{2}$ is calculated to be highly unfavorable enthalpically. ${ }^{49,50}$

In section S3 of the Supporting Information we describe the energetics of cyclic $\mathrm{O}_{4}$, which is calculated to be both thermodynamically and kinetically unstable toward fragmentation to two molecules of triplet $\mathrm{O}_{2}$. The $\mathrm{G} 4$ value for the endothermicity of the dimerization of triplet $\mathrm{O}_{2}$ to cyclic $\mathrm{O}_{4}$ is $93.6 \mathrm{kcal} / \mathrm{mol}$. Although the strain in the $\mathrm{O}_{4}$ ring certainly contributes to the unfavorability of this reaction, it should be noted that the G4 enthalpy of reaction $F$ in Table 1, for the tetramerization of $\mathrm{O}_{2}$ to cyclic $\mathrm{O}_{8}$, is calculated to be $94.6 \mathrm{kcal} /$ mol, even slightly more unfavorable. Note that the $\mathrm{O}_{2}$ oligomers discussed in this section are not the van der Waals complexes mentioned earlier ${ }^{20}$ but metastable molecules with covalent $\mathrm{O}-\mathrm{O} \sigma$ bonds.

Here we focus our detailed analysis on the formation of cyclic $\mathrm{O}_{6}$. The trimerization of $\mathrm{O}_{2}$ involves the formation of three new $\mathrm{O}-\mathrm{O} \sigma$ bonds, but at the sacrifice of $3 \times 100.6=$ $301.8 \mathrm{kcal} / \mathrm{mol}$ of resonance energy. If the difference between $301.8 \mathrm{kcal} / \mathrm{mol}$ and the $79.4 \mathrm{kcal} / \mathrm{mol}$ endothermicity of the trimerization reaction in equation $\mathrm{E}$ of Table 1 is assumed to be three times the average enthalpy of each of the three $\mathrm{O}-\mathrm{O} \sigma$ bonds that are made in the trimerization reaction, ${ }^{51}$ the average enthalpy of each of these three $\mathrm{O}-\mathrm{O}$ bonds is $(301.8-79.4) / 3$ $=74.1 \mathrm{kcal} / \mathrm{mol}$.

As a check on this value of the average $\mathrm{O}-\mathrm{O}$ bond enthalpy in the chair conformation of $\mathrm{O}_{6}$, we have computed the $\mathrm{G} 4$ value for the bond dissociation enthalpy of the central $\mathrm{O}-\mathrm{O}$ bond of a chairlike geometry of $\mathrm{HOO}-\mathrm{OOH}$ to two molecules of ${ }^{\bullet} \mathrm{OOH}^{52}$ This is the reverse of reaction G in Table 1 . The calculated enthalpy of the reverse reaction is $15.4 \mathrm{kcal} / \mathrm{mol}$.

However, reaction A of Table 1 indicates that each of the two - $\mathrm{OOH}$ molecules formed by the reverse of reaction $\mathrm{G}$ in Table 1 is resonance-stabilized by $31.6 \mathrm{kcal} / \mathrm{mol}$, relative to a localized hydroxyl radical. Therefore, without the resonance stabilization of the two ${ }^{\circ} \mathrm{OOH}$ radicals, the BDE of the central bond of $\mathrm{HOO}-\mathrm{OOH}$ would be $2 \times 31.6+15.4=78.6 \mathrm{kcal} / \mathrm{mol}$. Thus, the BDE of the central $\mathrm{O}-\mathrm{O}$ bond of $\mathrm{HOO}-\mathrm{OOH}$ to two, hypothetical, localized, ${ }^{\circ} \mathrm{OOH}$ radicals is slightly higher than the average $\mathrm{O}-\mathrm{O} \mathrm{BDE}$ of $70.1 \mathrm{kcal} / \mathrm{mol}$ in the more rigidly constrained chair conformation of $\mathrm{O}_{6}$, but only by $4.5 \mathrm{kcal} /$ mol. $^{53}$

Why Does Triplet 'SS' Form Oligomers? Reactions L and $\mathrm{M}$ of Table 1 show that, in agreement with experiment, the oligomerization of ${ }^{\bullet} \mathrm{SS} \boldsymbol{}^{\bullet}$ to $\mathrm{S}_{6}$ and $\mathrm{S}_{8}$ is predicted by G4 calculations to be thermodynamically favorable. The calculated enthalpy changes are $-70.8 \mathrm{kcal} / \mathrm{mol}$ for trimerization of triplet - $\mathrm{SS}^{\bullet}$ to $\mathrm{S}_{6}$ and $-103.0 \mathrm{kcal} / \mathrm{mol}$ for tetramerization to $S_{8}$.

If the very high resonance energy of triplet ${ }^{\bullet} \mathrm{OO}^{\bullet}$ is what keeps it from trimerizing to cyclic $\mathrm{O}_{6}$ and $\mathrm{O}_{8}$, is oligomerization of triplet ${ }^{\bullet} \mathrm{SS} \boldsymbol{S}^{\bullet}$ to cyclic $\mathrm{S}_{6}$ and $\mathrm{S}_{8}$ thermodynamically favorable because triplet ${ }^{\circ} \mathrm{SS}{ }^{\bullet}$ has a much lower resonance energy than triplet ${ }^{\circ} \mathrm{OO}^{\bullet}$ ? Comparisons of the $\mathrm{G} 4$ enthalpies of reactions $\mathrm{H}-\mathrm{K}$ in Table 1 with the enthalpies of reactions $\mathrm{A}-\mathrm{D}$ indicate that $\pi$ bond formation is only about half as stabilizing for $S-S \pi$ bonds as for $\mathrm{O}-\mathrm{O} \pi$ bonds. ${ }^{54,55}$

Of particular interest is that the resonance energy of triplet 'SS', as given by reaction $\mathrm{K}$ of Table 1 , is only $50.9 \mathrm{kcal} / \mathrm{mol}$. Thus, the resonance energy of triplet ${ }^{\bullet} \mathrm{SS}^{\bullet}$ is about $50 \mathrm{kcal} / \mathrm{mol}$ less than that of $100 \mathrm{kcal} / \mathrm{mol}$ in triplet ${ }^{\circ} \mathrm{OO}^{\bullet}$, as given by reaction $\mathrm{D}$ in Table 1 .

The difference between the G4 enthalpies of the trimerization reactions of $\mathrm{O}_{6}$ and $\mathrm{S}_{6}$ in Table 1 amounts to $79.4-(-70.8)=150.2 \mathrm{kcal} / \mathrm{mol}$. This is almost exactly the same as three times the difference of $50 \mathrm{kcal} / \mathrm{mol}$ between the resonance energies of $\mathrm{O}_{2}$ and $\mathrm{S}_{2}$. Therefore, the $50 \mathrm{kcal} / \mathrm{mol}$ difference between the resonance energies of $\mathrm{O}_{2}$ and $\mathrm{S}_{2}$ can account quantitatively for the difference of $150 \mathrm{kcal} / \mathrm{mol}$ between the enthalpies of their trimerization reactions.

Since this is the case, it must be that the average S-S $\sigma$ BDE in cyclic $\mathrm{S}_{6}$ is nearly the same as the average $\mathrm{O}-\mathrm{O} \sigma \mathrm{BDE}$ in cyclic $\mathrm{O}_{6}$. In order to confirm that these two BDEs are nearly the same, we computed the enthalpy for dissociation of the S$S$ bond in the chairlike conformation of HSS-SSH. As shown in Table 1 for reaction $\mathrm{N}$, this $\mathrm{S}-\mathrm{S} \mathrm{BDE}$ is $41.2 \mathrm{kcal} / \mathrm{mol}$.

However, the two $\mathrm{HSS}^{\bullet}$ radicals formed are each resonancestabilized to the extent of $17.5 \mathrm{kcal} / \mathrm{mol}$, as given by reaction $\mathrm{H}$ in Table 1. Therefore, the S-S $\sigma$ BDE of the chairlike conformation of HSS-SSH to two, hypothetical, unstabilized, - $\mathrm{SSH}$ radicals would be $2 \times 17.5+41.2=76.2 \mathrm{kcal} / \mathrm{mol}$. This $\mathrm{S}-\mathrm{S} \sigma \mathrm{BDE}$ is almost the same as the $\sigma \mathrm{BDE}$ of $78.6 \mathrm{kcal} / \mathrm{mol}$ for the cleavage of the $\mathrm{O}-\mathrm{O}$ bond in the chairlike conformation of $\mathrm{HOO}-\mathrm{OOH}$, without the stabilization energy of the two - $\mathrm{OOH}$ radicals formed.

The similarity of these intrinsic $\mathrm{S}-\mathrm{S}$ and $\mathrm{O}-\mathrm{O} \sigma$ BDEs strongly supports the hypothesis that the $150 \mathrm{kcal} / \mathrm{mol}$ difference between the G4 heats of the trimerization reactions of triplet ${ }^{\bullet} \mathrm{OO}^{\bullet}$ and triplet ${ }^{\bullet} \mathrm{SS}{ }^{\bullet}$ is due to the $150 \mathrm{kcal} / \mathrm{mol}$ difference between the resonance energies of three moles of $\mathrm{O}_{2}$ and three moles of $S_{2}$.

Why Are the Reactions of $\mathrm{O}_{2}$ To Form Water Highly Exothermic? In the foregoing sections of this manuscript, we have stressed that thermochemistry makes ${ }^{\bullet} \mathrm{OO}^{\bullet}$ remarkably unreactive toward hydrogen atom abstraction. For example, as already noted, reaction $\mathrm{D}$ of Table 1 shows that abstraction of two hydrogen atoms by triplet ${ }^{\bullet} \mathrm{OO}^{\bullet}$ is ca. $100 \mathrm{kcal} / \mathrm{mol}$ less favorable enthalpically than the same reaction of two ${ }^{\circ} \mathrm{OH}$ radicals. In fact, as discussed above, this comparison provides a reasonable definition of the resonance energy of the pair of three-electron, two-center bonds in ${ }^{\circ} \mathrm{OO}^{\bullet}$, including the $37-38$ $\mathrm{kcal} / \mathrm{mol}$ synergistic interaction between them in equation $\mathrm{C}$ of Table 1.

As shown in reaction $\mathrm{O}$ of Table 2, the $100 \mathrm{kcal} / \mathrm{mol}$ resonance energy of ${ }^{\bullet} \mathrm{OO}^{\bullet}$ makes the reaction of ${ }^{\bullet} \mathrm{OO}^{\bullet}$ with

Table 2. Enthalpies of Reaction, $\Delta H(298.15 \mathrm{~K})$ in $\mathrm{kcal} / \mathrm{mol}$, Obtained from Experimental Heats of Formation, $\Delta_{\mathrm{f}} H^{\circ}(298.15 \mathrm{~K})$, and from G4 Calculations

\begin{tabular}{clrc} 
& & \multicolumn{2}{c}{$\Delta H(298.15 \mathrm{~K})$} \\
\cline { 3 - 4 } reaction label & \multicolumn{1}{c}{ reaction } & G4 value & ATcT value \\
$\mathrm{O}$ & $\mathrm{H}_{2}+{ }^{\bullet} \mathrm{OO} \bullet \rightarrow \mathrm{HOOH}$ & -31.6 & -32.4 \\
$\mathrm{P}$ & $\mathrm{H}_{2}+\mathrm{HOOH} \rightarrow 2 \mathrm{H}_{2} \mathrm{O}$ & -83.3 & -83.2 \\
$Q$ & $2 \mathrm{H}_{2}+{ }^{\circ} \mathrm{OO} 0^{\bullet} \rightarrow 2 \mathrm{H}_{2} \mathrm{O}$ & -114.9 & -115.6 \\
$\mathrm{Q}$ & $\mathrm{H}_{2} \mathrm{O}_{2} \rightarrow 2 \cdot{ }^{\bullet} \mathrm{OH}$ & 48.9 & 49.4 \\
\hline
\end{tabular}

$\mathrm{H}_{2}$, to form $\mathrm{HOOH}$, exothermic by only about $32 \mathrm{kcal} / \mathrm{mol}$. However, as every general chemistry student learns, the reaction of ${ }^{\bullet} \mathrm{OO}^{\bullet}$ with two moles of $\mathrm{H}_{2}$, to form two moles of water, is hugely exothermic. As shown in reaction $\mathrm{Q}$ of Table 2 , the overall exothermicity amounts to about $115 \mathrm{kcal} / \mathrm{mol}$, a 
factor of 3.6 more than the exothermicity of reaction $\mathrm{O}$ in Table 2.

The reason for the much greater exothermicity of reaction $Q$ than reaction $\mathrm{O}$ is that reaction $\mathrm{P}$, the formation of two moles of water from the reaction of the hydrogen peroxide with $\mathrm{H}_{2}$, is exothermic by $83 \mathrm{kcal} / \mathrm{mol}$. Since reactions $\mathrm{O}$ and $\mathrm{P}$ both involve the breaking of the bond in $\mathrm{H}_{2}$ and the formation of two $\mathrm{O}-\mathrm{H}$ bonds, what accounts for the $51 \mathrm{kcal} / \mathrm{mol}$ greater exothermicity of reaction $\mathrm{P}$ than reaction $\mathrm{O}$ in Table 2?

The answer is not hard to find. Breaking the pair of threeelectron, two-center $\pi$ bonds in $\mathrm{O}_{2}$ costs $100 \mathrm{kcal} / \mathrm{mol}$, as shown by reaction $\mathrm{D}$ in Table 1 . However, reaction $\mathrm{R}$ in Table 2 shows that breaking the weak $\mathrm{O}-\mathrm{O} \sigma$ bond in $\mathrm{HOOH}$ costs only $49 \mathrm{kcal} / \mathrm{mol}$. The difference of $51 \mathrm{kcal} / \mathrm{mol}$ accounts very nicely for the difference in enthalpy between reaction $\mathrm{O}$ in Table 2, which breaks the pair of strong, three-electron, twocenter $\pi$ bonds in ${ }^{\circ} \mathrm{OO}^{\bullet}$, and reaction $\mathrm{P}$, which breaks the weak $\mathrm{O}-\mathrm{O} \sigma$ bond in $\mathrm{HOOH}$. Thus, what makes ${ }^{\circ} \mathrm{OO}^{\bullet}$ a very unusual molecule is not only its triplet ground state but also that, as first pointed out by Pauling, ${ }^{56}$ the $\pi$ bonding in this diradical is actually stronger than the $\sigma$ bonding. ${ }^{57}$

This is the reverse of the situation in organic molecules. For example, using the heats of formation in the ATcT, ${ }^{22}$ the enthalpy of the reaction

$$
\mathrm{H}_{2} \mathrm{C}=\mathrm{CH}_{2}+\mathrm{H}_{3} \mathrm{C}-\mathrm{CH}_{3} \rightarrow 2 \mathrm{H}_{3} \mathrm{C}-\mathrm{CH}_{2}{ }^{\bullet}
$$

is $\Delta H=64.9 \mathrm{kcal} / \mathrm{mol}$. The enthalpy of the reaction in eq 16 is the Benson definition of the strength of the $\pi$ bond in ethylene. ${ }^{58}$ The difference between the enthalpy of this reaction and that of $\Delta H=174.8 \mathrm{kcal} / \mathrm{mol}$ for the reaction

$$
\mathrm{H}_{2} \mathrm{C}=\mathrm{CH}_{2} \rightarrow 2{ }^{3} \mathrm{CH}_{2}
$$

is $109.9 \mathrm{kcal} / \mathrm{mol}$; and this can be taken to be the energy of the $\sigma$ bond in ethylene. Thus, the $\sigma$ bond of ethylene is $45.0 \mathrm{kcal} /$ mol stronger than the $\pi$ bond, which is the exact opposite of the situation in ${ }^{\circ} \mathrm{OO}^{\circ}$.

The strong $\pi$ bonding in ${ }^{\bullet} \mathrm{OO}^{\bullet}$ is, as discussed in this manuscript, the reason that this triplet diradical is persistent. On the other hand, the weak $\sigma$ bond allows the formation of two molecules of $\mathrm{H}_{2} \mathrm{O}$ from ${ }^{\bullet} \mathrm{OO}^{\bullet}$ to deliver large amounts of energy. The unusual combination of these two properties is what gives ${ }^{\bullet} \mathrm{OO}^{\bullet}$ the ability to support the existence of aerobic life on this planet.

\section{CONCLUSIONS}

The $37-38 \mathrm{kcal} / \mathrm{mol}$ exothermicity, calculated by G4 and deduced from experimental heats of formation, for reaction $\mathrm{C}$ in Table 1 provides a simple rationalization for the experimental fact that triplet ${ }^{\bullet} \mathrm{OO}^{\bullet}$ does not abstract hydrogen atoms, to form ${ }^{\circ} \mathrm{OOH}$, under reaction conditions in which peroxyl radicals $\left({ }^{\circ} \mathrm{OOH}\right)$ do abstract hydrogen atoms, to form $\mathrm{HOOH}$.

The ca. $100 \mathrm{kcal} / \mathrm{mol}$ of resonance stabilization of triplet ${ }^{\bullet} \mathrm{OO}^{\bullet}$, relative to the localized radical centers in two hydroxyl radicals (reaction $\mathrm{D}$ in Table 1 ), explains why trimerization of triplet ${ }^{\bullet} \mathrm{OO}^{\bullet}$ is computed to be endothermic by $79.4 \mathrm{kcal} / \mathrm{mol}$. On the other hand, the $51 \mathrm{kcal} / \mathrm{mol}$ resonance energy of triplet ' $\mathrm{SS}$, relative to the localized radical centers in two thiyl radicals (reaction $\mathrm{K}$ in Table 1 ), is only about half that of triplet ${ }^{\circ} \mathrm{OO}^{\bullet}$; and this difference in stabilization energies is responsible for the fact that trimerization of triplet ${ }^{\circ} \mathrm{SS}^{\bullet}$ is computed to be exothermic by $70.8 \mathrm{kcal} / \mathrm{mol}$.
The very large resonance stabilization of triplet ${ }^{\bullet} \mathrm{OO}^{\bullet}$ is largely a consequence of the pair of two-center, three-electron bonds in this diradical. However, the overall resonance stabilization of $\mathrm{O}_{2}$ is $100 \mathrm{kcal} / \mathrm{mol}$, which is between 37 and $38 \mathrm{kcal} / \mathrm{mol}$ greater than the resonance stabilization of two molecules of ${ }^{\circ} \mathrm{OOH}$. In $\mathrm{MO}$ theory most of this additional stabilization of triplet ${ }^{\bullet} \mathrm{OO}^{\bullet}$ comes from correlation between a pair of electrons, with opposite spins to those of the unpaired electrons, each of which occupies the bonding $\pi \mathrm{MO}$ of one of the two orthogonal $\pi$ systems in this diradical. Correlation between the motions of these two electrons minimizes their Coulombic repulsion energy.

In VB theory the explanation of the very large stabilization of triplet ${ }^{\bullet} \mathrm{OO}^{\bullet}$ is similar to that given in MO theory. Two nonzwitterionic resonance structures dominate the higher energy zwitterionic structures in the $\mathrm{VB}$ wave function for triplet 'OO'.

The $100 \mathrm{kcal} / \mathrm{mol}$ resonance energy of the triplet ${ }^{\bullet} \mathrm{OO}^{\bullet}$ diradical, which stabilizes it kinetically against both hydrogen atom abstraction and oligomerization, can be viewed as an important reason why $\mathrm{O}_{2}$ is abundant in the atmosphere of earth. The fact that $\mathrm{O}_{2}$ currently constitutes $20.94 \%$ of earth's atmosphere makes it readily available to participate in the oxidation reactions that form $\mathrm{CO}_{2}$ and $\mathrm{H}_{2} \mathrm{O}$ from organic molecules.

The weakness of the $\sigma$ bond in ${ }^{\bullet} \mathrm{OO}^{\bullet}$ and in the peroxides formed from it makes the oxidation reactions that generate $\mathrm{CO}_{2}$ and $\mathrm{H}_{2} \mathrm{O}$ from the reactions of ${ }^{\bullet} \mathrm{OO}{ }^{\bullet}$ with organic molecules highly exothermic, despite the large loss of resonance energy that is associated with addition reactions to this triplet diradical. Consequently, it is the unusual combination of strong $\pi$ bonding and weak $\sigma$ bonding in ${ }^{\circ} \mathrm{OO}^{\bullet}$ that enables this molecule to provide the chemical energy that sustains all of the aerobic forms of life on earth.

\section{ASSOCIATED CONTENT}

\section{Supporting Information}

The Supporting Information is available free of charge on the ACS Publications website at DOI: 10.1021/jacs.7b04232.

Experimental heats of formation, what Linus Pauling had to say about ${ }^{\bullet} \mathrm{OO}^{\bullet}, \mathrm{O}_{4}$ cyclic dimer of $\mathrm{O}_{2}, \mathrm{O}_{6}$ and $\mathrm{O}_{8}$ cyclic oligomers of $\mathrm{O}_{2}$, examples of unreactivity of $\mathrm{O}_{2}$, and what accounts for the large difference between the $\mathrm{O}-\mathrm{O} \sigma$ BDEs in $\mathrm{O}_{2}$ and in $\mathrm{HOOH}$ (PDF)

\section{AUTHOR INFORMATION}

\section{Corresponding Authors}

*Weston.Borden@unt.edu

*rh34@cornell.edu

ORCID

Weston Thatcher Borden: 0000-0003-4782-3381

Roald Hoffmann: 0000-0001-5369-6046

Bo Chen: 0000-0002-5084-1321

\section{Notes}

The authors declare no competing financial interest.

\section{ACKNOWLEDGMENTS}

We thank Dr. Sheila Borden for stimulating discussions about the reactivity of ${ }^{\circ} \mathrm{OO}^{\bullet}$. W.T.B. acknowledges the generous support of his research by Grant B0027 from the Robert A. Welch Foundation. R.H. and B.C. are grateful to the National 
Science Foundation for its support of the Cornell research through Grant CHE-1305872. T.S. acknowledges the Research Foundation-Flanders (FWO) for a position as research assistant (11ZG615N).

\section{REFERENCES}

(1) Expressed as mole fraction of dry air. Source is the Earth System Research Laboratory of NOAA, NASA, U.S. DOE: https://www.esrl. noaa.gov/gmd/ccgg/about/co2 measurements.html.

(2) Krusic, P. J.; Wasserman, E.; Keizer, P. N.; Morton, J. R.; Preston, K. F. Science 1991, 254, 1183.

(3) Frei, R.; Gaucher, C.; Poulton, S. W.; Canfield, D. E. Nature 2009, 461, 250-253.

(4) Sosa Torres, M. E.; Saucedo-Vázquez, J. P.; Kroneck, P. M. H. Sustaining Life on Planet Earth: Metalloenzymes Mastering Dioxygen and Other Chewy Gases; Springer International Publishing: Switzerland, 2015; pp 1-12.

(5) (a) Bell, R. P. Proc. R. Soc. London, Ser. A 1936, 154, 414

(b) Evans, M. G.; Polanyi, M. Trans. Faraday Soc. 1936, 32, 1333.

(6) Brewer, L. Chem. Rev. 1953, 52, 1-75.

(7) Chaston, J. C. Platinum Metals Rev. 1964, 8, 50-54.

(8) Schmidt-Rohr, K. J. Chem. Educ. 2015, 92, 2094-2099.

(9) Sutton, G. P.; Biblarz, O. Rocket Propulsion Elements; John Wiley \& Sons: Hoboken, NJ, 2016.

(10) Or is it $451^{\circ} \mathrm{C}$ ? See the spirited discussion in https://en. wikipedia.org/wiki/Talk\%3AAutoignition_temperature.

(11) The autoignition temperature, the $T$ at which a molecule spontaneously ignites in the absence of an initiating spark or radical source, is $206{ }^{\circ} \mathrm{C}$ for $n$-octane, $363{ }^{\circ} \mathrm{C}$ for ethanol, $498{ }^{\circ} \mathrm{C}$ for benzene: Lide, D. R., Ed. The Handbook of Chemistry and Physics, 85th ed.; CRC Press: Boca Raton, 2004; section 16, pp 16-31.

(12) DeMore, W. B.; Bayes, K. D. J. Phys. Chem. A 1999, 103, 26492654.

(13) Reviews: (a) Borden, W. T., Ed. Diradicals; Wiley-Interscience: New York, 1982. (b) Abe, M. Chem. Rev. 2013, 113, 7011-7088.

(14) Reviews: (a) Simmie, J. M. Prog. Energy Combust. Sci. 2003, 29, 599-634. (b) Miller, J. A.; Pilling, M. J.; Troe, J. Proc. Combust. Inst. 2005, 30, 43-88. (c) Pilling, M. J. Proc. Combust. Inst. 2009, 32, 2744.

(15) Glassman, I.; Yetter, R. A.; Glumac, N. G. Combustion, 5th ed.; Academic Press: Waltham, MA, 2015.

(16) Law, C. K. Combustion physics; Cambridge University Press: Cambridge, U.K., 2010.

(17) Pryor, W. A.; Stanley, J. P.; Blair, E. Lipids 1976, 11, 370-379.

(18) (a) Bolland, J. L.; Gee, G. Trans. Faraday Soc. 1946, 42, 236.

(b) Bolland, J. L.; Gee, G. Trans. Faraday Soc. 1946, 42, 244.

(c) Bolland, J. L. Proc. R. Soc. London, Ser. A 1946, 186, 218.

(d) Bolland, J. L. Trans. Faraday Soc. 1948, 44, 669. (e) Bolland, J. L. Q. Rev., Chem. Soc. 1949, 3, 1.

(19) The formation of $\mathrm{O}_{2}$ dimers was an early suggestion of Lewis, in thinking about the magnetic susceptibility of oxygen. Lewis, G. N. J. Am. Chem. Soc. 1924, 46, 2027.

(20) We provide here some leading references. Dimer: (a) Biennier, L.; Romanini, D.; Kachanov, A.; Campargue, A.; Bussery-Honvault, B.; Bacis, R. J. Chem. Phys. 2000, 112, 6309-6321. Aquilanti, V.; Ascenzi, D.; Bartolomei, M.; Cappelletti, D.; Cavalli, S.; Vitores, M. d. C.; Pirani, F. Phys. Rev. Lett. 1999, 82, 69-72. Trimer: (b) HernándezLamoneda, R.; Pérez-Ríos, J.; Carmona-Novillo, E.; Bartolomei, M.; Campos-Martínez, J.; Hernández, M. Chem. Phys. 2012, 399, 80-85. Tetramer: (c) Bartolomei, M.; Carmona-Novillo, E.; Hernández, M. I.; Pérez-Ríos, J.; Campos-Martínez, J.; Hernández-Lamoneda, J. Phys. Rev. B: Condens. Matter Mater. Phys. 2011, B84, 092105.

(21) Chemically bonded rings of composition $\mathrm{O}_{3}, \mathrm{O}_{4}, \mathrm{O}_{6}, \mathrm{O}_{8}$, very much unstable with respect to $\mathrm{nO}_{2}$, are also local minima; we will return to these below.

(22) http://atct.anl.gov/Thermochemical\%20Data/version\%201. 118/index.php.
(23) See, for example: Borden, W. T. J. Phys. Chem. A 2017, 121, 1140.

(24) Curtiss, L. A.; Redfern, P. C.; Raghavachari, K. J. Chem. Phys. 2007, 126, 084108.

(25) NIST Computational Chemistry Comparison and Benchmark DataBase: Calculations: cccbdb.nist.gov/geom2.asp. Experiment: cccbdb.nist.gov/exp2.asp.

(26) A good example may be found in the provocative work of Klaus Schmidt-Rohr, ref 8, who argues for considering $\mathrm{O}_{2}$, and not hydrocarbons, energy-rich in combustion reactions.

(27) Massey, J. T.; Bianco, D. R. J. Chem. Phys. 1954, 22, 442.

(28) For a very recent review of odd electron bonds, see: Clark, T. ChemPhysChem 2017, DOI: 10.1002/cphc.201700417.

(29) Filatov, M.; Reckien, W.; Peyerimhoff, S. D.; Shaik, S. J. Phys. Chem. A 2000, 104, 12014.

(30) (a) Pauling, L. J. Am. Chem. Soc. 1931, 53, 1367. (b) Pauling, L. The Nature of the Chemical Bond, 2nd ed.; Cornell University Press: Ithaca, 1944; pp 61, 272-274. Pauling, L. The Nature of the Chemical Bond, 3rd ed.; Cornell University Press: Ithaca, 1960; pp 92, 340-354.

(31) Nevertheless, the correct explanation of why the ground state of - $\mathrm{OO}^{\bullet}$ is a triplet was provided by: Lennard-Jones, J. E. Trans. Faraday Soc. 1929, 25, 668.

(32) The situation is analogous to that in the pair of one-electron $\pi$ bonds in triplet $\mathrm{B}_{2}$.

(33) With inclusion of the overlap integral, $S$, between the AOs, the normalization factor for each of these bonding $\pi$ MOs would be $(2+$ $2 S)^{-1 / 2}$, rather than $2^{-1 / 2}$

(34) With inclusion of the overlap integral, $S$, between the AOs, the normalization factor for each of these antibonding $\pi^{*}$ MOs would be $(2-2 S)^{-1 / 2}$, rather than $2^{-1 / 2}$.

(35) If the $\pi$ MOs in eq 6 and the $\pi^{*}$ MOs in eq 7 are normalized with inclusion of the overlap integral, ${ }^{33,34}$ a value of $\lambda$ of less than 1 is required in order to obtain eq 13.

(36) (a) Heitler, W.; Pöschl, G. Nature 1934, 133, 833. (b) Nordheim-Pöschl, G. Ann. Phys. 1936, 418, 258-280.

(37) Wheland, G. W. Trans. Faraday Soc. 1937, 33, 1499.

(38) Shaik, S.; Hiberty, P. C. Helv. Chim. Acta 2003, 86, 1063.

(39) Shaik, S.; Hiberty, P. C. Rev. Comput. Chem. 2004, 20, 1-100.

(40) Su, P.; Song, L.; Wu, W.; Hiberty, P. C.; Shaik, S. J. Comput. Chem. 2007, 28, 185-197. These authors attribute the large amount of resonance stabilization of triplet ${ }^{\bullet} \mathrm{OO}^{\bullet}$ to the fact that the pair of three-electron, two-center bonds in this molecule are "charge-shift" bonds.

(41) Shaik, S.; Hiberty, P. C. A Chemist's Guide to Valence Bond Theory; John Wiley \& Sons: Hoboken, NJ, 2008; p 94.

(42) Goddard, W. A., III; Ladner, R. C. J. Am. Chem. Soc. 1971, 93, $6750-6756$.

(43) Goddard and co-workers have, in fact, applied GVB theory to creating wave functions that correctly describe the dissociation of the lowest singlet and triplet states of $\mathrm{O}_{2}$ to the ground state of two oxygen atoms. Moss, B. J.; Bobrowicz, F. W.; Goddard, W. A., III J. Chem. Phys. 1975, 63, 4632-4639.

(44) McWeeny, R. J. Mol. Struct.: THEOCHEM 1991, 229, 29.

(45) Harcourt, R. D. J. Phys. Chem. 1992, 96, 7616.

(46) Although, as discussed in the text, it might be argued that destabilization of $\mathrm{H}_{2} \mathrm{O}_{2}$ by lone-pair repulsions contributes to the exothermicity of reaction $\mathrm{A}$ in Table 1 , the major contributor to the exothermicity of reaction $\mathrm{D}$ is not reaction $\mathrm{A}$ but reaction $\mathrm{B}$; and $\mathrm{H}_{2} \mathrm{O}_{2}$ does not appear in reaction $\mathrm{B}$. Moreover, $\mathrm{H}_{2} \mathrm{O}_{2}$ is one of the products of the disproportionation of $\mathrm{HOO}^{\bullet}$ in reaction $\mathrm{C}$, but the formation of $\mathrm{O}_{2}$ as the other product makes this reaction exothermic by $37-38$ $\mathrm{kcal} / \mathrm{mol}$.

(47) Kistiakowsky, G. B.; Ruhoff, J. R.; Smith, H. A.; Vaughan, W. E. J. Am. Chem. Soc. 1936, 58, 146.

(48) Harcourt has provided a similar type of rationalization for the instability of cyclic $\mathrm{O}_{6}$, relative to three molecules of triplet $\mathrm{O}_{2}$. Harcourt, R. D. Educhem 1981, 2 (3), 2.

(49) There have been previous discussions in the literature of oxygen oligomers, from cyclic $\mathrm{O}_{3}$ to cyclic $\mathrm{O}_{8}$. For cyclic ozone see: 
(a) Goddard, J. D.; Chen, X.; Orlova, G. J. Phys. Chem. A 1999, 103, 4078-4084. (b) Siebert, R.; Schinke, R; Bittererova, M. Phys. Chem. Chem. Phys. 2001, 3, 1795-1798. For cyclic $\mathrm{O}_{4}, \mathrm{O}_{6}$, and $\mathrm{O}_{8}$, see, inter alia: (c) Seidl, E.; Schaefer, H. F., III J. Chem. Phys. 1988, 88, 70437049. (d) Gadzhiev, O. B.; Ignatov, S. K.; Kulikov, M. Y.; Feigin, A. M.; Razuvaev, A. G.; Sennikov, P. G.; Schrems, O. J. Chem. Theory Comput. 2013, 9, 247-62. (e) Ochoa-Calle, A. J.; Ramírez-Solis, A. Chem. Phys. Lett. 2014, 592, 326-329.

(50) There is also a substantial literature on the bonding (and loss of magnetism, and coloration) that develops in oxygen under pressure. Leading references here are: (a) Meng, Y.; Eng, P. J.; Tse, J. T.; Shaw, D. M.; Hu, M. Y.; Shu, J.; Gramsch, S. A.; Kao, C.; Hemley, R. J.; Mao, H. Proc. Natl. Acad. Sci. U. S. A. 2008, 105, 11640-11644. (b) Lundegaard, L. F.; Weck, G.; McMahon, M. I.; Desgreniers, S.; Loubeyre, P. Nature 2006, 443, 201.

(51) A more precise analysis would have to include the changes that occur when the $\sigma$ bonds of three $\mathrm{O}_{2}$ molecules are transformed into three of the $\sigma$ bonds of $\mathrm{O}_{6}$.

(52) (a) The hydrogen tetraoxide molecule $(\mathrm{HOOOOH})$ has been synthesized and characterized by Raman spectroscopy: Levanov, A. V.; Sakharov, D. V.; Dashkova, A. V.; Antipenko, E. E.; Lunin, V. V. Eur. J. Inorg. Chem. 2011, 2011, 5144-50. (b) The results of calculations of the equilibrium constant for the dimerization of $\mathrm{HOO}^{\bullet}$ to $\mathrm{HO}_{4} \mathrm{H}$ have been reported: Sprague, M. K.; Irikura, K. K. J. Phys. Chem. A 2015, 119, 7052-62 and references cited therein. (c) The dimerization of two peroxyl radicals, ${ }^{\circ} \mathrm{OOR}$, to form the tetraoxide, ROOOOR, is, in fact, the chain terminating step in autooxidation reactions. For a very interesting theoretical study of why the fate of the tetraoxide depends on whether $\mathrm{R}$ contains a secondary or tertiary carbon attached to $\mathrm{O}$, see: Lee, R.; Gryn'ova, G.; Ingold, K. U.; Coote, M. L. Phys. Chem. Chem. Phys. 2016, 18, 23673-79.

(53) It should be noted that the average $\mathrm{O}-\mathrm{O}$ bond energy in $\mathrm{O}_{6}$ and the value of what the $\mathrm{BDE}$ of the central bond in $\mathrm{HOO}-\mathrm{OOH}$ would be, without the resonance stabilization of the ${ }^{\bullet} \mathrm{OOH}$ radicals formed when this bond breaks, are both considerably larger than the $\mathrm{O}-\mathrm{O} \mathrm{BDE}$ of $48.9 \mathrm{kcal} / \mathrm{mol}$ in $\mathrm{H}_{2} \mathrm{O}_{2}$ (reaction $\mathrm{R}$ in Table 2). Donation of lone pairs of electrons from the oxygens $\alpha$ to an $\mathrm{O}-\mathrm{O}$ bond into the $\sigma^{*}$ orbital of the bond provides stabilization of the lone pairs on the oxygens that flank each of the $\mathrm{O}-\mathrm{O}$ bonds in $\mathrm{O}_{6}$ and in $\mathrm{HOO}-\mathrm{OOH}$.

(54) Using the Wolfsberg-Helmholtz approximation for estimating the strengths of bonding interactions, most or all of this difference in $\mathrm{S}-\mathrm{S}$ and $\mathrm{O}-\mathrm{O} \pi$ bond strengths can be attributed to the fact that sulfur is less electronegative than oxygen. Wolfsberg, M.; Helmholz, L. J. J. Chem. Phys. 1952, 20, 837.

(55) Nevertheless, Pratt and co-workers have found that hydropersulfides (RSSH) react exothermically with peroxyl radicals to form hydroperoxyls and persulfide radicals: Chauvin, J.-P. R.; Griesser, M.; Pratt, D. A. J. Am. Chem. Soc. 2017, 139, 6484-93. Indeed, using the G4 energies in Table $\mathrm{S} 1$ of the Supporting Information, the reaction $\cdot \mathrm{OOH}+\mathrm{HSSH} \rightarrow \mathrm{HOOH}+{ }^{\bullet} \mathrm{SSH}$ is calculated to be exothermic by $13.5 \mathrm{kcal} / \mathrm{mol}$, despite the fact that comparison of reactions $\mathrm{A}$ and $\mathrm{H}$ in Table 1 indicates that the ${ }^{\circ} \mathrm{OOH}$ radical has $14 \mathrm{kcal} / \mathrm{mol}$ greater resonance stabilization than the ${ }^{\bullet} \mathrm{SSH}$ radical. The explanation for the finding that the more resonance stabilized radical reacts to form the less resonance stabilized radical is that an $\mathrm{S}-\mathrm{H}$ bond (e.g., in $\mathrm{H}_{2} \mathrm{~S}$ ) is, according to the heats of formation in Table $S 1,28 \mathrm{kcal} / \mathrm{mol}$ weaker than an $\mathrm{O}-\mathrm{H}$ bond (e.g., in $\mathrm{H}_{2} \mathrm{O}$ ).

(56) Pauling, L. The Nature of the Chemical Bond, 3rd ed.; Cornell University Press: Ithaca, 1960; p 92.

(57) The ATcT value of $\Delta_{\mathrm{f}} H^{\circ}(298.15 \mathrm{~K})$ for an oxygen atom is 59.6 $\mathrm{kcal} / \mathrm{mol}^{22}$ which means that the $\mathrm{BDE}$ of triplet ${ }^{\circ} \mathrm{OO}^{\bullet}$ to two atoms of ${ }^{3} \mathrm{P}{ }^{\bullet} \mathrm{O}^{\bullet}$ is $119.2 \mathrm{kcal} / \mathrm{mol}$. If the $\pi \mathrm{BDE}$ in ${ }^{\bullet} \mathrm{OO}^{\bullet}$ is $100 \mathrm{kcal} / \mathrm{mol}$, then the $\mathrm{BDE}$ of the $\sigma$ bond is only $19 \mathrm{kcal} / \mathrm{mol}$, which is about 30 $\mathrm{kcal} / \mathrm{mol}$ less than that of the $\mathrm{O}-\mathrm{O} \sigma$ bond in $\mathrm{HOOH}$ in reaction $\mathrm{R}$ of Table 2. One of the contributors to this large difference in $\mathrm{O}-\mathrm{O} \sigma$ BDEs is discussed in section S-6 of the Supporting Information.

(58) (a) Benson, S. W. J. Chem. Educ. 1965, 42, 502. (b) Benson, S. W. Thermochemical Kinetics, 2nd ed.; Wiley: New York, 1976; pp 63-
65. (c) Benson's thermochemical value of the $\pi \mathrm{BDE}$ in ethylene is essentially the same as the value that was obtained from the kinetics of the $E-Z$ isomerization of ethylene-1,2- $d_{2}$ by: Douglas, J. E.; Rabinovitch, B. S.; Looney, F. S. J. Chem. Phys. 1955, 23, 315. 